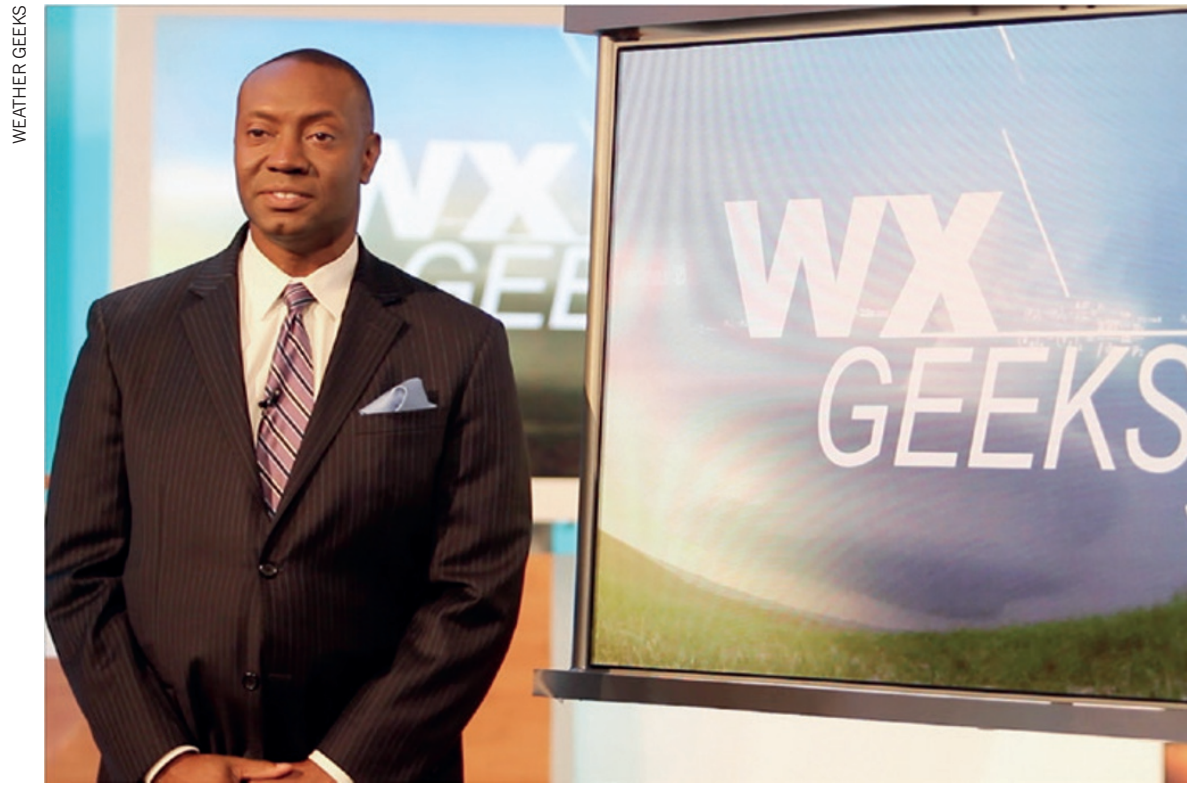

Meteorologist J. Marshall Shepherd, host of Weather Geeks, is comfortable advocating for science.

unforeseen benefits: Krkosek says that he has become more adept at separating his emotional and intellectual responses - a skill that has been useful in both his career and his personal life.

Kathie Dello, associate director of the Oregon Climate Change Research Institute in Corvallis, has also learned how to deal with criticism. She gives public talks that highlight the regional impacts of climate change, and she has had some harrowing in-person and e-mail encounters with the public and researchers, in which her understanding of the science behind her assertions has been questioned. After a negative encounter, she allows herself only a short amount of time to process it and to salvage any lessons from the experience. (She has learned, for example, to request a moderator at public forums.) Then she moves on. She has also learned that a game of dodgeball can be cathartic.

\section{VALUED OPINIONS}

There is little doubt that the greater a scientist's standing, the greater the impact their words will have - and, conversely, the lower a scientist's standing, the more potentially devastating any fallout from their words will be for their career. Perhaps not surprisingly, many scientists wait until they are in senior positions to use their voices.

J. Marshall Shepherd, a meteorologist at the University of Georgia in Athens, had published dozens of papers and had received a presidential award of excellence, but becoming president of the American Meteorological Society gave him a platform to amplify his voice. He now writes opinion pieces, is active on social media and hosts a television show called Weather Geeks. He advises younger scientists to do two things when deciding whether to speak up for science - establish scientific credibility and carefully evaluate whether they have the unshakeable temperament that is necessary for times when they may be challenged.

Wildlife biologist Chris Darimont at the University of Victoria in Canada frequently speaks out on trophy hunting and other controversial issues that he has studied, and has engaged in live radio and television debates with trophy-hunting advocates. But before he secured his tenure-track position, he worried about the backlash he could receive for such public speaking, and the long fingerprints it would leave on the web. "When people are assessing you for a job, it's not just your CV they are reviewing, it's any controversy online as well," he says. He eventually concluded that efforts to engage constructively in the public sphere could shine through, too. "I accepted that I would take the good with the bad," he says. He also finds it productive to engage with policy-makers. "Thinking some decision makers are going to find your paper in a journal, understand it and use it to make evidence-based decisions borders on absurd," he says.

Ultimately, scientists who speak out create room at the table for evidence, say those who have found their voice. "If we aren't there speaking on the science," says Shepherd, "people skilled in messaging, such as attorneys and lawyers, will fill the gaps."

Virginia Gewin is a freelance writer based in Portland, Oregon.

1. Hall Jamieson, K. \& Hardy, B. W. Proc. Natl Acad. Sci. USA 111 (Suppl. 4), 13598-13605 (2014).

2. Worm, B. et al. Science 314, 787-790 (2006).

3. Worm, B. et al. Science 325, 578-585 (2009).

4. Scott-Phillips, T. C. Evolution 68, 1231-1243 (2014).

5. Krkosek, M., Lewis, M. A. \& Volpe, J. P. Proc. Biol. Sci. 272, 689-696 (2005).

\section{CAREER DECISIONS}

\section{Of academic interest}

A survey of 1,500 recent US biomedical $\mathrm{PhD}$ graduates found that white and Asian men, who are well represented in academic institutions, are most likely to show interest in becoming academic researchers (K. D. Gibbs et al. PLoS ONE 9, e114736; 2014). Although scientists of all ethnicities reported losing interest in faculty careers as their doctoral studies continued, women's loss of interest was more pronounced, particularly for underrepresented minorities. The trend persisted after controlling for factors such as publication record and a sense of belonging. Understanding why career interests differ is crucial for increasing diversity, says study co-author Kimberly Griffin of the University of Maryland, College Park.

\section{GRANTS}

\section{Paint me a picture}

Applicants for US National Institutes of Health (NIH) grants will now be asked to contextualize past work, which could help early-career researchers. A revised 'biosketch' section instructs scientists to explain how their experience will allow them to accomplish the proposal's goals. Sally Rockey, the NIH's deputy director for extramural research, has said that the change puts focus on an applicant's skills and accomplishments, not just their publications. The format is being rolled out in January and will become mandatory for most NIH grants on 25 May. Online tools such as SciENcv have been updated to help applicants to create biosketches that can be used across various government agencies.

\section{HIGHER EDUCATION}

\section{UK science numbers up}

Between 2003 and 2012, UK student enrolment in the biological and physical sciences rose by more than $30 \%$ and overall university enrolment rose by more than $6 \%$, according to a report by the country's Higher Education Statistics Agency. But across all fields, the number of postgraduate researchers increased by only $0.1 \%$ for $2012-13$, the smallest increase since 2004. In the decade since 2003, enrolment at UK institutions fell sharply for students from the Middle East $(-124 \%)$, Asia (-63\%), Africa (-36\%) and North America (-31\%), but rose for students from Australasia (22\%) and South America (21\%). 